\title{
CHAPADA DOS GUIMARÃES: BORDA DA BACIA DO PARANÁ
}

\author{
Jurandyr Luciano Sanches Ross ${ }^{1}$
}

Resumo: A Chapada dos Guimarães corresponde a uma extensa superfície de relevo elevado e de topo aplanado posicionada na extremidade noroeste da bacia sedimentar do Paraná, localizada no Estado de Mato Grosso-Brasil. As formas planas do topo situam-se entre 600 e $800 \mathrm{~m}$ de altitude, com a superfície pouco inclinada para sul e leste, sendo esculpida predominantemente sobre arenitos do período Devoniano e Cretáceo. Suas bordas são escarpadas, sendo que as frentes são voltadas para a Depressão Cuiabana, ultrapassando $500 \mathrm{~m}$ de gradiente topográfico. Também existem nos topos formas de relevo ruiniformes esculpidas nos arenitos vermelhos e amarelos da Formação Ponta Grossa (Devoniano). A Chapada é contornada por Depressões como a Cuiabana e a Interplanáltica de Paranatinga a noroeste e norte, e também por Planaltos a noroeste e sul. Essas áreas são fortemente marcadas por feixes de falhas de direção NE-SW e possuem vinculações com as áreas de dobramentos do pré-Cambriano Superior, denominado por Cinturão Orogenético Paraguai-Araguaia. A região passou a ter reativações tectônicas a partir do mesocenozóico, com soerguimento generalizado e arqueamentos dômicos mais localizados, a exemplo do chamado "Arco de São Vicente". A morfogênese da Chapada têm fortes relações com o tectonismo de um lado e de outro com os ativos processos denudacionais concomitantes, responsáveis pelo rebaixamento erosivo das depressões e da intensa dissecação do relevo dos planaltos do entorno. Portanto, a Chapada dos Guimarães corresponde a um segmento de relevo da borda noroeste da Bacia do Paraná, que se manteve mais preservada dos processos de falhamentos e consequentemente das atividades erosivas meso-cenozóicas.

Palavras-chave: Chapada dos Guimarães, Tectônica Meso-Cenozóica, processos denudacionais.

Abstract: The Chapada dos Guimarães corresponds to a large area of high relief and flattened tops located at the northwest border of the Paraná Sedimentary Basin in the State of Mato Grosso, Brazil. The flattened tops are between 600 and $800 \mathrm{~m}$ of altitude, with the surface slightly tilted to the south and east carving predominantly Devonian and Cretaceous sandstones. Its edges are steep, and the fronts are geared towards the Cuiabana Depression, exceeding $500 \mathrm{~m}$ of topographic gradient. There are also at the tops ruiniform reliefs carved in red and yellow sandstones of Ponta Grossa Formation (Devonian). The Chapada is surrounded by Cuiabana and Interplanaltica of Paranatinga Depressions in the northwest and north, as well as Plateaus to northwest and south. These areas are heavily marked by lineaments of NE-SW faults and they have connections with Precambrian Superior folding areas, named as Paraguay-Araguaia Orogenic Belts. Since the Meso-Cenozoic the region has had tectonic reactivations, with general uplifting and localized domic bendings as the so-called "Arc of Saint Vincent". The Chapada's morphogenesis has strong relationships with tectonics and active denudational processes, the latter responsible for the lowering of erosive depressions and the intense surrounding plateau dissections. Therefore, the Chapada dos Guimarães landform corresponds to a relief segment of the northwest border of the Paraná Basin, which remained preserved over processes of faulting and consequently MesoCenozoic erosive activities..

\footnotetext{
${ }^{1}$ Professor Titular. Universidade de São Paulo - USP.
} 
Keywords: Chapada dos Guimarães, Meso-Cenozoic tectonics, denudational processes.

\section{INTRODUÇÃO:CONTEXTO GEOGRÁFICO}

A denominada Chapada dos Guimarães caracteriza extensa superfície de relevo plano a pouco dissecado posicionada no topo de uma região de planaltos na borda norte-noroeste da Bacia Sedimentar do Paraná, no Estado de Mato Grosso, Brasil. A condição de apresentar formas de relevo com amplas áreas planas, com baixa densidade de canais de drenagem e em posição altimétrica elevada com altitudes oscilando entre 600-800m é o que lhe confere tal denominação. As chapadas estão quase que invariavelmente posicionadas nas bordas das grandes bacias sedimentares brasileiras, encontrando-se preferencialmente na região central do país, com destaque para as bordas norte e noroeste da Bacia do Paraná, borda sul da Bacia do Parecis e nas bordas sul, oeste e sudeste da Bacia do Parnaíba. Na Bacia Sedimentar da Amazônia oriental tais ocorrências são incipientes.

Além de apresentarem topos elevados e planos, as chapadas são demarcadas em suas bordas por escarpas abruptas frequentemente decorrentes da conjugação de processos tectônicos mesocenozoicos e denudacionais associados às alternâncias climáticas seco-úmido, atuando em estratos rochosos sedimentares de diferentes resistências.

A Chapada dos Guimarães é quase que totalmente delimitada por escarpas, estabelecendo conexão com superfícies de relevo mais baixas e aplanadas do entorno denominadas genericamente de Depressões Periféricas, com planaltos s que ocupam posições topográficas inferiores. As depressões normalmente se posicionam entre as bordas escarpadas das chapadas de um lado e das formas de morros mais elevados e serras alongadas do outro.

A oeste da Chapada encontra-se a Depressão Cuiabana, denominação derivada do rio Cuiabá que a drena, sendo que ao norte encontra-se a Depressão Interplanáltica de Paranatinga. Estas depressões, cujas altitudes variam de 150 a $400 \mathrm{~m}$, se posicionam entre as escarpas da Chapada dos Guimarães e o relevo montanhoso da denominada Província Serrana de Mato Grosso. Este relevo é mantido por antigas estruturas orogênicas datadas do Proterozóico Superior, compondose por uma grande quantidade de cristas monoclinais mantidas por estruturas em anticlinais escavados e sinclinais alçadas. Tal morfoestrutura define arranjo regional de característica montanhosa linear e estreita, em forma de extenso arco com concavidade voltada para sudeste, delimitada por inúmeras serras paralelas entre si, sustentadas por estruturas rochosas de arenitos altamente silicificados. 
A região centro-oeste do Brasil onde se encontra a Chapada dos Guimarães tem como domínio fitoclimático as Savanas Tropicais, que recebem a denominação regional de Cerrados. A vegetação natural que recobre as terras mais planas e altas da Chapada são as Savanas abertas, onde as árvores e os arbustos de troncos retorcidos ocorrem de forma bastante espaçadas e o solo é recoberto por gramíneas de folhas estreitas e alongadas, conhecidas por capim barba de bode. Estas acompanham as margens dos cursos d'água (matas ciliares ou galerias, também conhecidas por veredas).

Nos relevos planos, os solos tendem a ser muito profundos, com textura argilosa ou areno-argilosa de coloração vermelho-escura ou vermelho-amarela, denominados por Latossolos, com elevada concentração de óxido de ferro e alumínio. Estes solos apresentam excelente estabilidade mecânica para as práticas agrícolas, mas são de baixa fertilidade natural, com características de pH ácido.

Em função das condições físicas dos solos, e de extensas áreas de relevos planos, a superfície da chapada configura área preferencial para agricultura mecanizada de grãos (soja/milho) e de fibras (algodão). Entretanto, no extremo noroeste apresentam-se relevos ruiniformes esculpidos em arenitos rígidos de coloração vermelha, de aspecto paisagístico de significativa beleza cênica. A combinação destas formas de relevo, com as escarpas com mais de $500 \mathrm{~m}$ de gradiente topográfico, os mirantes naturais que se abrem para a Depressão Cuiabana oferecendo visão panorâmica, juntamente com cursos fluviais com águas cristalinas, cachoeiras, piscinas naturais e temperaturas elevadas na maior parte do ano, torna esse conjunto de atributos forte atrativo turístico regional e nacional.

O clima é distinguido por duas estações, sendo uma seca e outra chuvosa. As chuvas concentramse de outubro a abril, quando ocorrem $80 \%$ do total anual. Ao longo do ano o volume de chuvas oscila entre 1300 mm/ano nas terras baixas das depressões circundantes, a 1600 mm/ano nas partes mais elevadas da chapada.

As temperaturas são elevadas quase o ano todo, observando-se valores mais altos, sobretudo, nos meses de transição secos para os úmidos e vice-versa.No geral, as temperaturas médias anuais máximas estão entre 35 e $38^{\circ} \mathrm{C}$, enquanto que as médias anuais mínimas absolutas estão entre 17 e $20^{\circ} \mathrm{C}$. Na superfície das depressões circundantes, a sensação de calor é mais acentuada do que no alto da chapada, onde o efeito orográfico e a circulação dos ventos são mais intensos, com as temperaturas tornando-se mais amenas oferecendo maior conforto térmico, sobretudo no período noturno. 
As escarpas ao redor da chapada apresentam vertentes com declividades elevadas, geralmente acima de $30^{\circ}$, sendo intensamente dissecadas por vales estreitos e profundos. Nos setores mais elevados, as escarpas apresentam feições de paredões abruptos e verticais com declividades que se aproximam dos $90^{\circ}$. Nestes relevos as rochas estão expostas, enquanto que nos setores mais dissecados, os solos são rasos e pedregosos. Nos fundos de vale ocorre cobertura vegetal de matas tropicais de encostas, ao passo que nos interflúvios prevalecem savanas.

Nas depressões circundantes, os solos são rasos, frequentemente pedregosos, ácidos e muito ferruginosos. A cobertura vegetal constitui-se por Savanas abertas e nas margens fluviais prevalecem matas ciliares ou veredas.

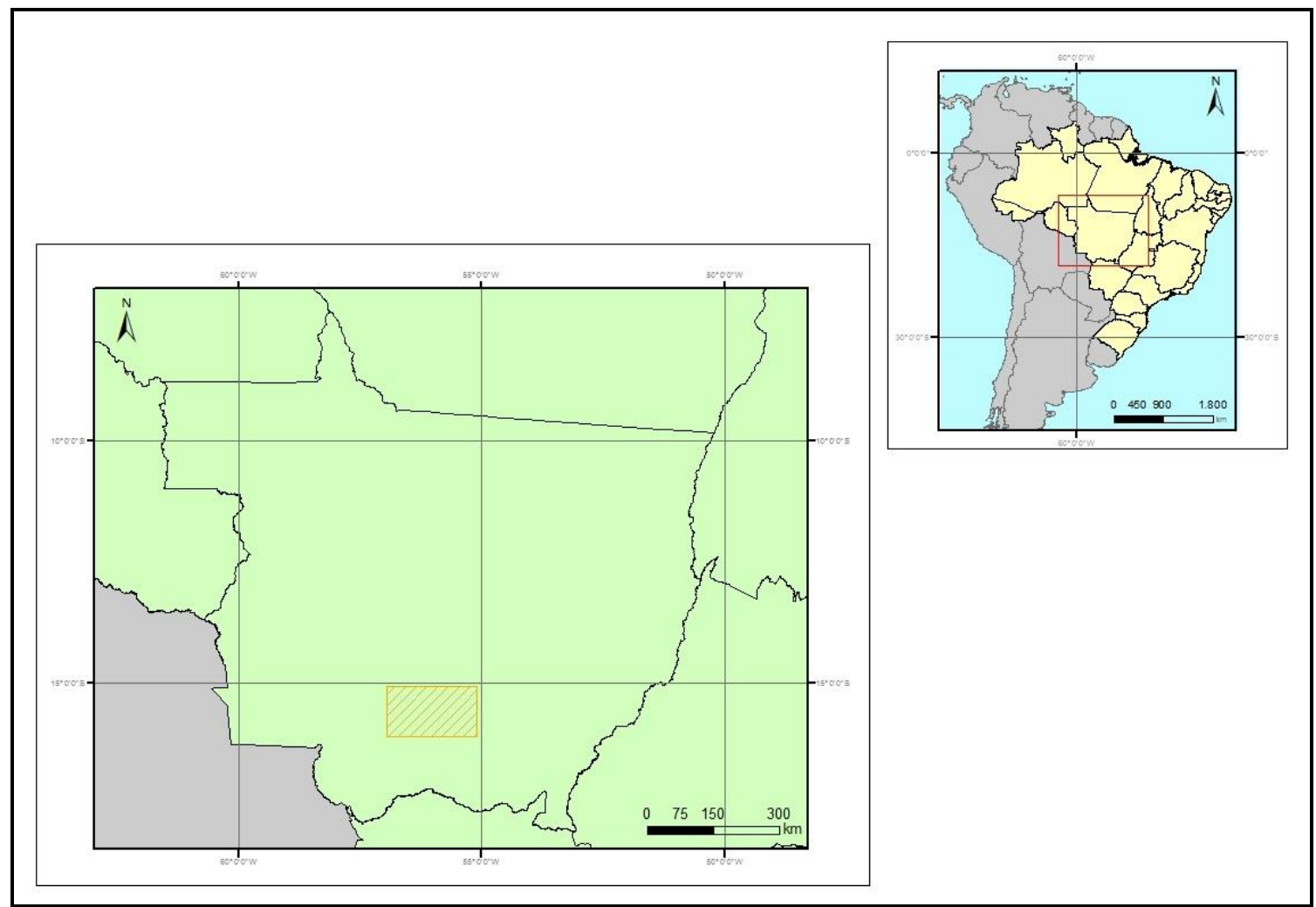

Figura 1- mapa de localização da chapada.

\section{Formas do Relevo e Relações Estruturais}

A Chapada dos Guimarães é a área mais elevada e preservada dos planaltos do noroeste da Bacia Sedimentar do Paraná. Perfazendo o macro-compartimento do Planalto dos Guimarães, existem três unidades de relevo, conforme ROSS \& SANTOS (1982): a própria Chapada dos Guimarães, o Planalto dos Alcantilados e o Planalto do Casca, sendo o segundo posicionado ao sul da Chapada e o terceiro a noroeste da mesma. 


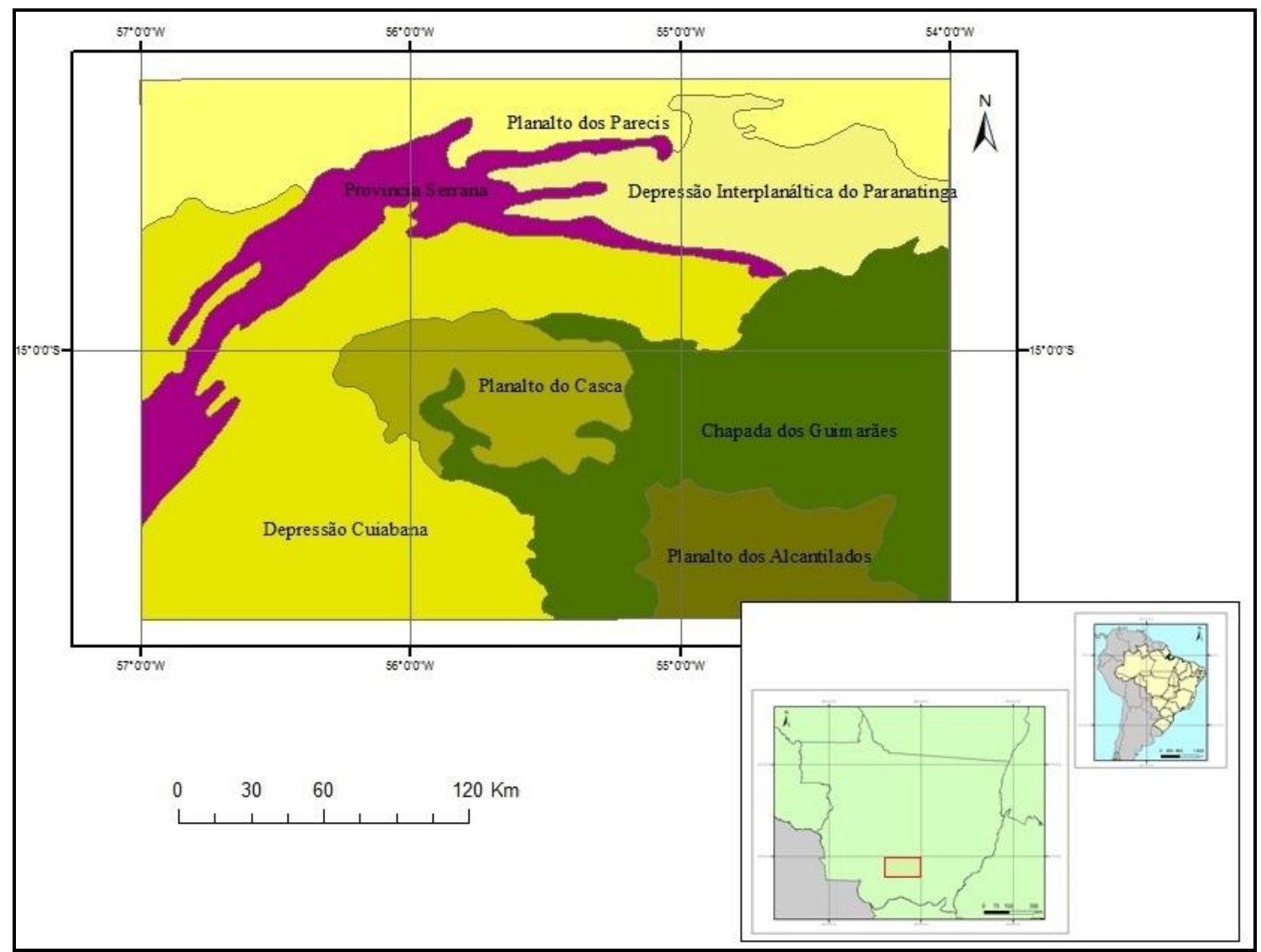

Figura 2-Mapa de Unidades do Relevo da Chapada dos Guimarães e arredores.

As formas do relevo do topo da Chapada são preferencialmente planas a pouco dissecadas, com as vertentes em tênue convexidade, onde as declividades dominantes estão abaixo de $5^{\circ}$ ou $~ 10 \%$. A densidade de canais de drenagem é muito baixa e os vales são pouco entalhados, comportando com certa freqüência pequenas planícies fluviais. A extensão leste-oeste da Chapada possui 200 Km e na direção norte-sul extensão de $40 \mathrm{Km}$ nos trechos mais estreitos, mas chega a $120 \mathrm{Km}$ no setor sudoeste. Toda a área é drenada pelo rio das Mortes, que a secciona no sentido oeste-leste, onde a bacia hidrográfica se define por fraco entalhamento e adensamento fluvial.

A Chapada é contornada por escarpas abruptas de altitudes muito variadas, onde afloram as rochas sedimentares do Devoniano das Formações Furnas e Ponta Grossa. Essas rochas estão representadas por arenitos finos a muito finos e subordinadamente por argilitos, folhelhos e carbonatos, tendo suas origens relacionadas à fase marinha dos depósitos sedimentares da Bacia do Paraná. As escarpas são mais elevadas no setor noroeste, na face voltada para a Depressão Cuiabana, onde o gradiente topográfico ultrapassa os $500 \mathrm{~m}$, pois enquanto a superfície de topo nessa região encontra-se a mais de $800 \mathrm{~m}$ de altitude, a base posiciona-se a $250 \mathrm{~m}$ na Depressão Cuiabana. Essas escarpas são com frequência determinadas por linhas de falhas sobre as quais 
atuam processos erosivos plúvio-fluviais, imprimindo padrão de relevo de forte dissecação em forma de vales muito profundos e estreitos, conjugados na parte superior com paredões rochosos abruptos. Nesse setor noroeste, o terço inferior da escarpa está esculpida em metassedimentos do Grupo Cuiabá, representado por metarenitos, filitos e quartzitos do Pré-Cambriano Superior. Estas mesmas rochas aparecem no setor norte, apenas na base da escarpa, enquanto que no setor sul a morfoescultura age nos arenitos do Devoniano.

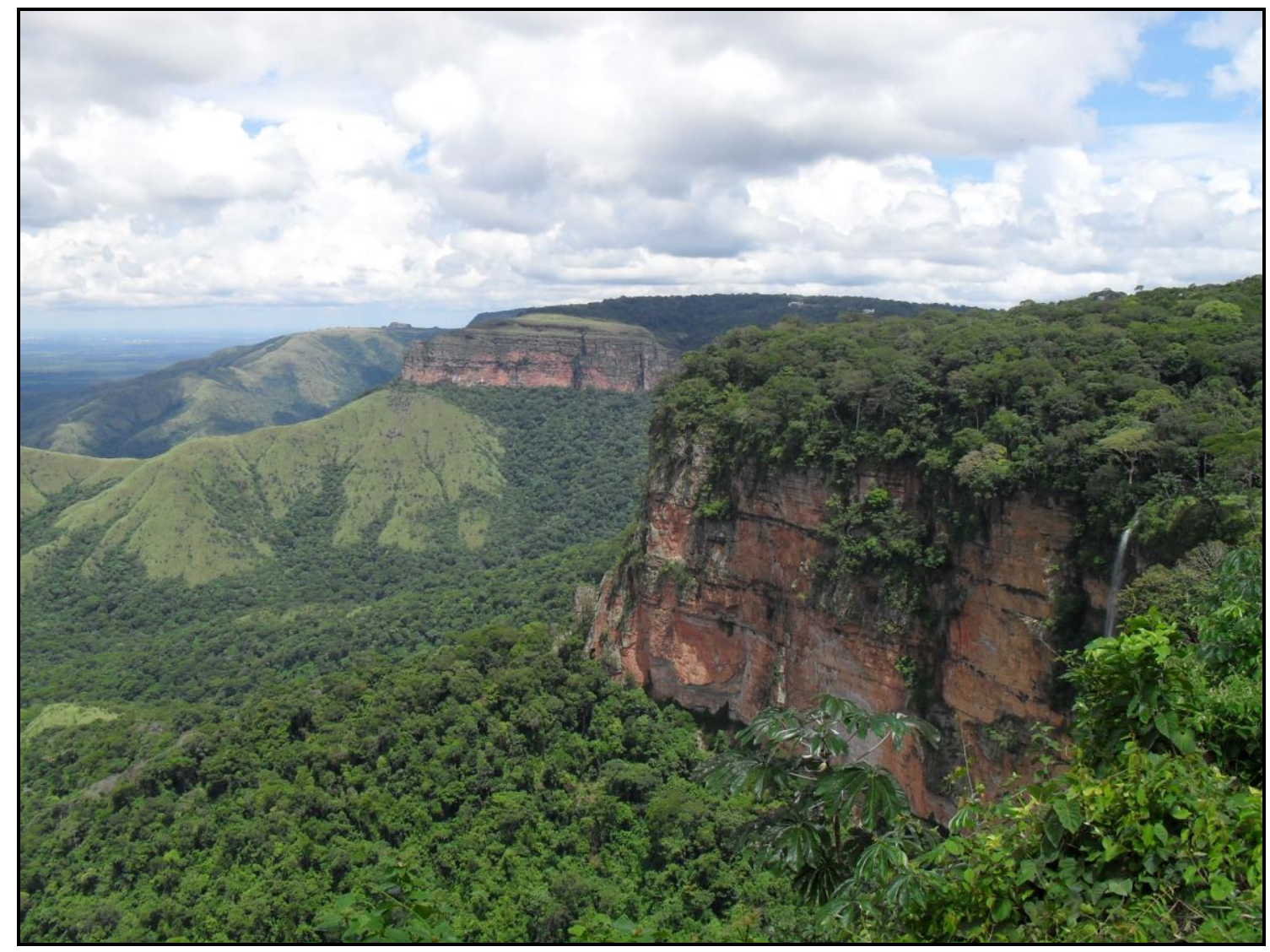

Foto 1 - Escarpa da Chapada dos Guimarães.

No extremo noroeste da Chapada dos Guimarães, nas proximidades da cidade de mesmo nome, é encontrada significativa ocorrência de relevos com morfologia ruiniforme, oferecendo feições geomorfológicas que dão à paisagem marcante beleza cênica produzida pelas formas residuais esculpidas nos arenitos vermelho-amarelos da Formação Ponta Grossa. Esse conjunto de pequenas formas, juntamente com as frentes escarpadas abruptas voltadas para a Depressão Cuiabana, fornece para esse setor da Chapada dos Guimarães um significativo atrativo turístico e de importante interesse como patrimônio geológico-geomorfológico. 


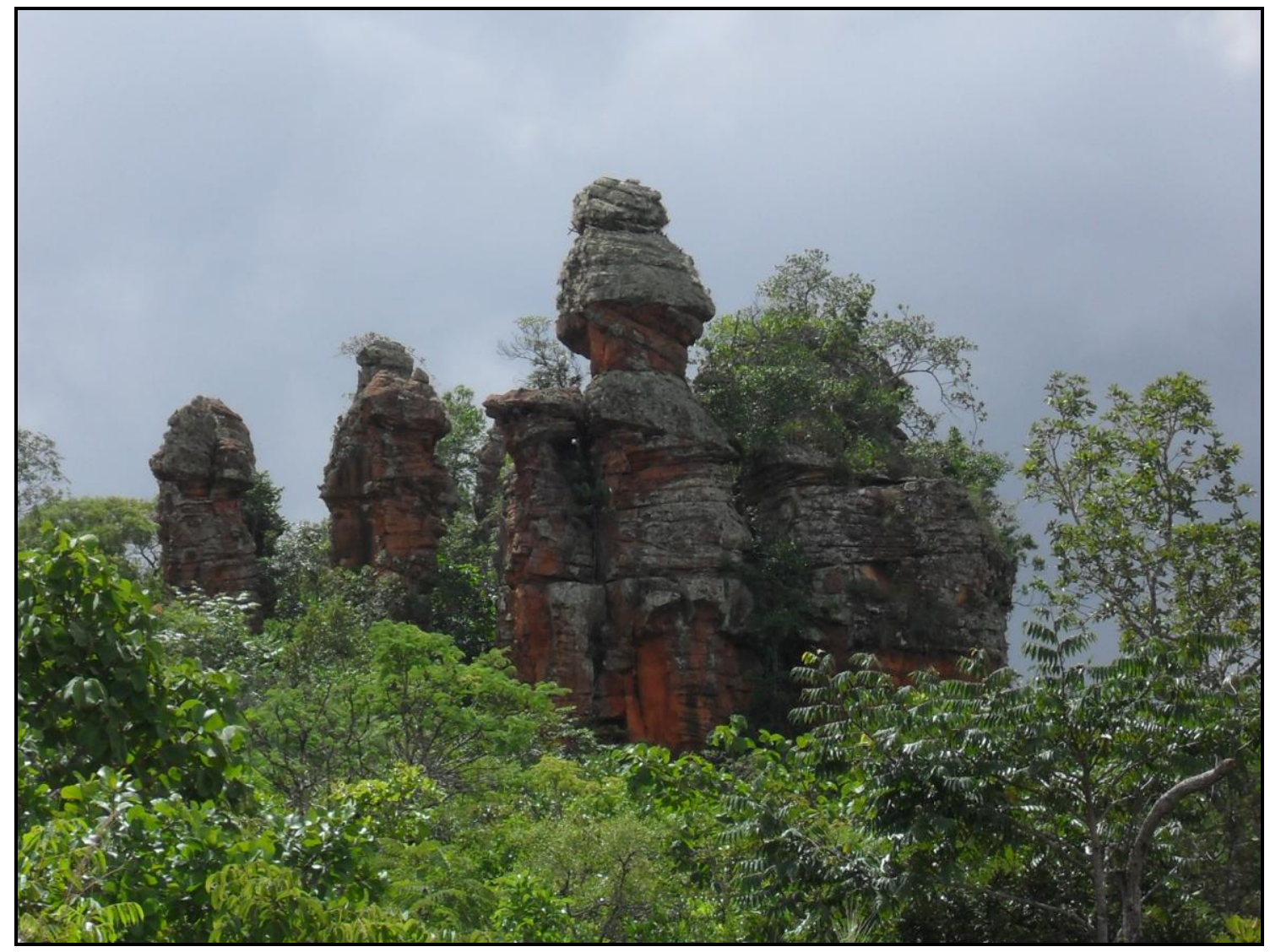

Foto 2 - Relevo ruiniforme da Chapada.

Os estratos sedimentares que recobrem o topo são pouco espessos, estando representados pelos arenitos de origem continental pertencentes ao Grupo Bauru (Cretáceo). Há a ocorrência de outra camada sotoposta pouco espessa e descontínua, correspondendo aos sedimentos argilosos vermelho-escuros, ricos em material ferruginoso contendo em seu interior, de forma descontínua, horizontes concrecionários nodulares. Estes sedimentos finos de cobertura de topo, cuja camada não ultrapassa $20 \mathrm{~m}$ de espessura, foram inicialmente classificados como formação sedimentar do Terciário com a denominação de Formação Cachoeirinha, identificada por OLIVEIRA \& MUHLMANN (1965). Nos mapeamentos do Projeto Radambrasil, estas ocorrências receberam a denominação de TQdl - sedimentos Terciário-Quartenários detrítico-lateríticos (BRASIL, 1982). Esses sedimentos recobrem dominantemente os setores mais elevados e conservados das amplas colinas de topos tabulares ou planos da Chapada, e são os responsáveis pelos Latossolos Vermelho-Escuros e Latossolos Vermelho-Amarelos de textura argilosa que se estendem por toda a área. Nas vertentes longas e de pouca declividade também se encontram os solos arenosos derivados dos arenitos do Grupo Bauru, que se distribuem pelas áreas mais baixas dessas vertentes, próximas aos fundos de vale. 
Observa-se ainda a ocorrência de pequenos ressaltos topográficos em forma de anfiteatros escarpados, com no máximo 20 m de altura, delimitando as cabeceiras de drenagem de alguns cursos fluviais tributários do rio das Mortes e de outros menores drenados na direção das escarpas. Essas formas são mantidas por afloramentos de espessos horizontes concrecionários ferruginosos, evidenciandoestas coberturas sedimentares argilo-ferruginosas.

A unidade geomorfológica denominada por Planalto dos Alcantilados foi utilizada pela primeira vez por ALMEIDA (1954). Esta denominação incluiu os relevos fortemente recortados por escarpas, patamares estruturais e relevos residuais com vertentes abruptas e topos planos posicionados ao sul da Chapada dos Guimarães, drenados pelas bacias dos rios São Lourenço e Poxoréo. Trata-se de uma unidade de relevo de feições morfológicas muito complexas, marcadas por escarpas alcantiladas (íngremes) com reversos em rampas nem sempre definidas, interrompidas por outras escarpas menores. No geral, constituem-se por formas tabulares descontínuas, ora com blocos estruturais expostos e mais elevados, ora com formas mais dissecadas e rebaixadas. Estas formas de relevo, de morfologias muito irregulares e distintas, são marcadas por alinhamentos de falha com direções preferenciais NE-SW, que delimitam patamares estruturais, morros residuais em forma de mesetas tabulares e setores rebaixados acompanhando os fundos de vale onde prevalecem colinas e morros de topos e vertentes convexas. Estes patamares estruturais têm vertentes escarpadas voltadas para oeste e seus reversos apresentam caimento topográfico e estrutural para leste. As litologias que dão sustentação a estas formas são arenitos e siltitos datados do Devoniano.

A partir da margem esquerda do rio São Lourenço para leste, pode-se definir três compartimentos de patamares estruturais. O mais baixo situa-se entre 300 e $400 \mathrm{~m}$, enquanto que o segundo é representado pelo reverso da escarpa da Serra das Parnaíbas com altitudes variando entre 300 e $500 \mathrm{~m}$;o terceiro situa-se acima de $500 \mathrm{~m}$, chegando a $650 \mathrm{~m}$, correspondendo a blocos estruturais soerguidos por efeito tectônico. Esses relevos, que assumem aspecto de elevada rugosidade topográfica e grande complexidade estrutural, são dominantemente mantidos pelos sedimentos do Devoniano representados pelos arenitos finos, siltitos e argilitos das Formações Furnas e Ponta Grossa, que neste setor encontram-se fortemente deformados pelos efeitos da tectônica meso-cenozóica.

O Planalto do Casca, localizado a noroeste da Chapada, posiciona-se em patamar intermediário entre o topo da mesma e a Depressão Cuiabana, definindo extenso anfiteatro produzido por erosão regressiva de arenitos do Grupo Bauru (Cretáceo) e Botucatu (Triássico). Corresponde a um 
setor bem marcado por rebaixamento erosivo, onde as altitudes oscilam entre 350 a $600 \mathrm{~m}$, sendo individualizado no contato com a Chapada por escarpas, com gradiente topográfico de aproximadamente $100 \mathrm{~m}$. O contato com a Depressão Cuiabana se faz através de superfície em rampa, drenada pelo rio Casca. A morfologia dominante neste planalto são colinas amplas de topos convexos, e em seus limites leste e sul, além das escarpas, também se encontram morros residuais de topos tabulares. Na transição da Chapada para os setores mais rebaixados deste Planalto, podem-se observar também alguns vales estreitos e profundos, formando verdadeiros canyons de origem fluvial.

As Depressões Cuiabana e Interplanáltica de Paranatinga, que contornam os planaltos e a Chapada dos Guimarães ao norte, noroeste e oeste, são unidades do relevo regional, que ajudam a explicar a existência da própria Chapada. Essas depressões se conectam com a Depressão do Alto Paraguai mais a oeste, interpenetrando-se pelas Serras Residuais do Alto Paraguai, conhecidas na literatura como Província Serrana de Mato Grosso. As depressões têm continuidade para o sul ao longo das bacias dos rios Cuiabá e Paraguai, onde passam a constituir vasta área plana e receptora de sedimentos quaternários denominada de Pantanal Matogrossense, ou Pantanal do Alto Paraguai. A superfície aplanada da Depressão Cuiabana possui nas proximidades do Pantanal altimetrias em torno de 150m em relação ao nível do mar, e ganha altitude através de extensa rampa para norte, na direção das nascentes dos rios Cuiabá e Paranatinga. Assim, as altitudes atingem 400 m nas partes mais elevadas da Depressão Cuiabana e em sua continuidade na Depressão Interplanáltica de Paranatinga, que se posiciona ao norte da Chapada.

As depressões apresentam relevo em forma de colinas amplas com vales pouco entalhados, vertentes com declividades muito baixas, normalmente abaixo de $5^{\circ}$ ou $10 \%$, e fundos de vale rasos. A densidade de canais de drenagem é bastante baixa, muito controlada pela estrutura subjacente, sendo a maioria dos canais de primeira e segunda ordenm com drenagem intermitente.

Essas formas de relevo de gradientes topográficos modestos, estão esculpidas nas rochas do Grupo Cuiabá, que correspondem aos metassedimentos, destacando-se os metarenitos, filitos e quartzitos, sendo frequentes os veios de quartzo na massa rochosa. A cobertura pedológica é marcada pela ocorrência de solos rasos, quase sempre recobertos por pavimentos detríticos de fragmentos de quartzo heterométricos originários dos veios existentes nas rochas basais. Nos horizontes superficiais desses solos também são freqüentes as ocorrências de concreções ferruginosas que ora aparecem expostas em superfície, ora ocorrem no interior do horizonte B dos 
mesmos. As rochas do grupo Cuiabá que dão suporte ao relevo e aos solos destas depressões, pois são a parte basal da faixa de dobramentos do Cinturão Orogenético Paraguai-Araguaia. Estas formações rochosas foram geradas a partir dos depósitos de clásticos em margens continentais, que sofreram dobramentos e metamorfismo no pré-Cambriano Superior na fase de consolidação do que se considera atualmente a plataforma continental brasileira composta por crátons e cinturões orogenéticos pré-Cambrianos. Os limites destas depressões com os sedimentos da Bacia do Paraná se fazem preferencialmente por contatos bruscos na base das escarpas, com exceção dos setores onde a passagem se faz através de patamares ligeiramente mais elevados, com concentração de quartzitos do Grupo Cuiabá. Essas duas depressões têm, portanto, limites a leste pelas escarpas da Chapada dos Guimarães e a oeste e norte pelas Serras Residuais do Alto Paraguai; esta é caracterizada pelaProvíncia Serrana de Mato Grosso, sustentada por rochas sedimentares dobradas do Grupo Alto Paraguai.

\section{Processos Estruturais e Esculturais: a gênese das formas}

Como se pode constatar, a Chapada dos Guimarães corresponde a uma unidade de relevo elevada e muito preservada na borda da Bacia do Paraná. Há outras superfícies elevadas e relativamente bem preservadas nas bordas desta bacia, como ocorre nos Estados de Mato Grosso do Sul, sudoeste de Goiás, oeste de Minas Gerais (triangulo mineiro), norte e centro-leste de São Paulo, Centro-oeste do Paraná, centro-oeste de Santa Catarina e norte-nordeste do Rio Grande do Sul. Essas áreas preservadas são testemunhos geomorfológicos de que a Bacia do Paraná foi progressivamente soerguida por eventos tectônicos a partir do Jura-Cretáceo e por todo o Cenozóico, pois além de estarem topograficamente elevadas são em grande parte recobertas por arenitos finos, argilitos e conglomerados basais do Cretáceo (Grupo Bauru). Nos Estados do Paraná, Santa Catarina e Rio Grande do Sul, essas superfícies aplanadas de topo na borda da bacia são mantidas por rochas vulcânicas ácidas (riolitos e andesitos), cuja origem está associada aos derrames vulcânicos fissurais do Jurássico que se estendem por toda a Bacia com predomínio de rochas básicas (basaltos e diabásios). Esses processos tectônicos vulcânicos e de soerguimentos generalizados e desiguais se iniciam com a abertura do Atlântico através da deriva dos continentes sul-americano e africano. A dinâmica da placa litosférica Sul- Americana e a subducção da Placa de Nazca no Pacífico, ao mesmo tempo em que possibilita a contínua formação da orogenia Andina, também redefine a configuração do continente sul-americano. 
Esse processo promove em todo o continente arqueamentos mais localizados e soerguimentos generalizados das estruturas rígidas que compõem o arcabouço geológico dos crátons e cinturões orogenéticos pré-Cambrianos, juntamente com as bacias sedimentares fanerozóicas aí existentes. Para interpretar a evolução do relevo brasileiro e em especial o da Chapada dos Guimarães, é preciso recuar ao menos à fase do Ciclo Brasiliano no Proterozóico Superior. Estas estruturas rígidas do complexo cristalino brasileiro se consolidaram de paraplataforma para ortoplataforma (ALMEIDA, 1967) no contexto do Supercontinente Gondwana. Neste tempo, os movimentos crustais geraram grandes faixas de dobramentos acompanhados de metamorfismos e magmatismos regionais, à semelhança do que ocorre atualmente com as formações das cadeias orogênicas dos Andes, Rochosas, Alpes e Himalaia, entre outras. Nesta condição, os sedimentos detríticos e carbonáticos depositados nas margens dos antigos continentes passaram por fortes pressões e elevadas temperaturas frente às movimentações continentais, transformando-se ao longo de alguns milhões de anos em cinturões orogenéticos. Estas estruturas têm em suas partes superiores rochas sedimentares dobradas e falhadas, e em suas partes inferiores rochas metamórficas oriundas de diferentes graus de metamorfismo. Neste processo tectônico deram-se, simultaneamente, as intrusões de massas ígneas subjacentes, que passaram a compor as raízes profundas das faixas dos dobramentos; quando estas atingiram a superfície através das linhas de fraqueza das estruturas dobradas, constituíram-se em áreas de atividades vulcânicas. No que hoje corresponde ao território brasileiro, essas áreas estão representadas por algumas grandes faixas orogênicas do Ciclo Brasiliano (550 a 900 Ma.), como o Cinturão do Atlântico, Brasília e ParaguaiAraguaia. Este último desperta particularmente interesse para a compreensão da morfogênese regional da área de estudo.

Esta faixa de dobramentos, que se estende por aproximadamente $2.500 \mathrm{Km}$, é composta por dois grandes grupos de formações rochosas, uma basal e mais antiga representada por metarenitos, filitos, quartzitos e intrusões de granitos (Grupo Cuiabá), e outra mais recente, constituída por arenitos finos, argilitos, calcáreos, dolomitos, arenitos silicificados, folhelhos, siltitos e arcósios (Grupo Alto Paraguai).

As macro-estruturas dobradas dos Grupos Cuiabá e Alto Paraguai foram submetidas a longos períodos erosivos, que promoveram significativos rebaixamentos das formas estruturais, levandoas a tornarem-se superfícies aplanadas durante o Paleozóico. O resultado destes desgastes podem ser testemunhados pela ocorrência de extensa superfície arrasada, aplanada e baixa representada pela Depressão Cuiabana e Interplanáltica de Paranatinga, onde os metassedimentos com 
diferentes graus de inclinação/mergulho foram erodidos e nivelados indistintamente pelas subseqüentes fases denudacionais. Nas formações Furnas e Ponta Grossa (Devoniano) repousam estratos plano-paralelos de forma discordante sobre os metassedimentos do Grupo Cuiabá; nas áreas correspondentes às atuais Depressões Cuiabana e Interplanáltica de Paranatinga os sedimentos devonianos não são mais encontrados. Conforme AB'SABER (1972), estas depressões e suas antigas superfícies de erosão foram exumadas com a retirada da cobertura sedimentar por processos denudacionais no pós-Cretáceo (Cenozóico). As depressões com essa gênese foram classificadas por AB' SÁBER (op. cit.) como Depressões Marginais de Eversão. Nos topos das Serras Residuais do Alto Paraguai/Província Serrana de Mato Grosso, identificou-se nos níveis altimétricos entre 600 e 800 m superfícies planas descontínuas e alinhamento de cristas monoclinais, niveladas nas bordas de anticlinais escavadas, nos dorsos arrasados de anticlinais, e no Val de sinclinais alçadas, que estão parcialmente recobertas por sedimentos do Cretáceo. Estas evidências encontradas em diferentes níveis altimétricos, sobre a Província Serrana levou ROSS (1987; 1991) a interpretá-las como decorrentes de fases erosivas pré-Cretáceas, inumadas por sedimentos arenosos continentais do Cretáceo (arenitos dos Grupos Parecis e Bauru). Como esses fragmentos residuais de antigas superfícies de erosão são encontradas tanto nas Depressões Cuiabana e Interplanáltica de Paranatinga como nos topos das Serras Residuais do Alto Paraguai (Província Serrana), ROSS (op. cit.) as interpretou como decorrentes de fases erosivas longas e generalizadas combinadas com processos tectônicos pós - ciclos erosivos. Estes promoveram soerguimentos de grande amplitude territorial com arqueamentos mais localizados, acompanhados de reativação de falhas antigas com deslocamentos verticais e longitudinais de grandes blocos estruturais.

Em resumo, considera-se que houve extensivas fases erosivas pré-devonianas que rebaixaram os metassedimentos do Grupo Cuiabá, seguidos pelos recobrimentos parciais dos sedimentos da Bacia do Paraná. Na Província Serrana os topos elevados e aplanados recobertos parcialmente pelos sedimentos do Cretáceo podem ter sido erodidos no pré-Devoniano e posteriormente soerguidos, ou os processos erosivos ocorreram em fases mais recentes entre o Devoniano e o Jurássico, sendo em seguida recobertos pelos arenitos do Cretáceo hoje em exumação. 


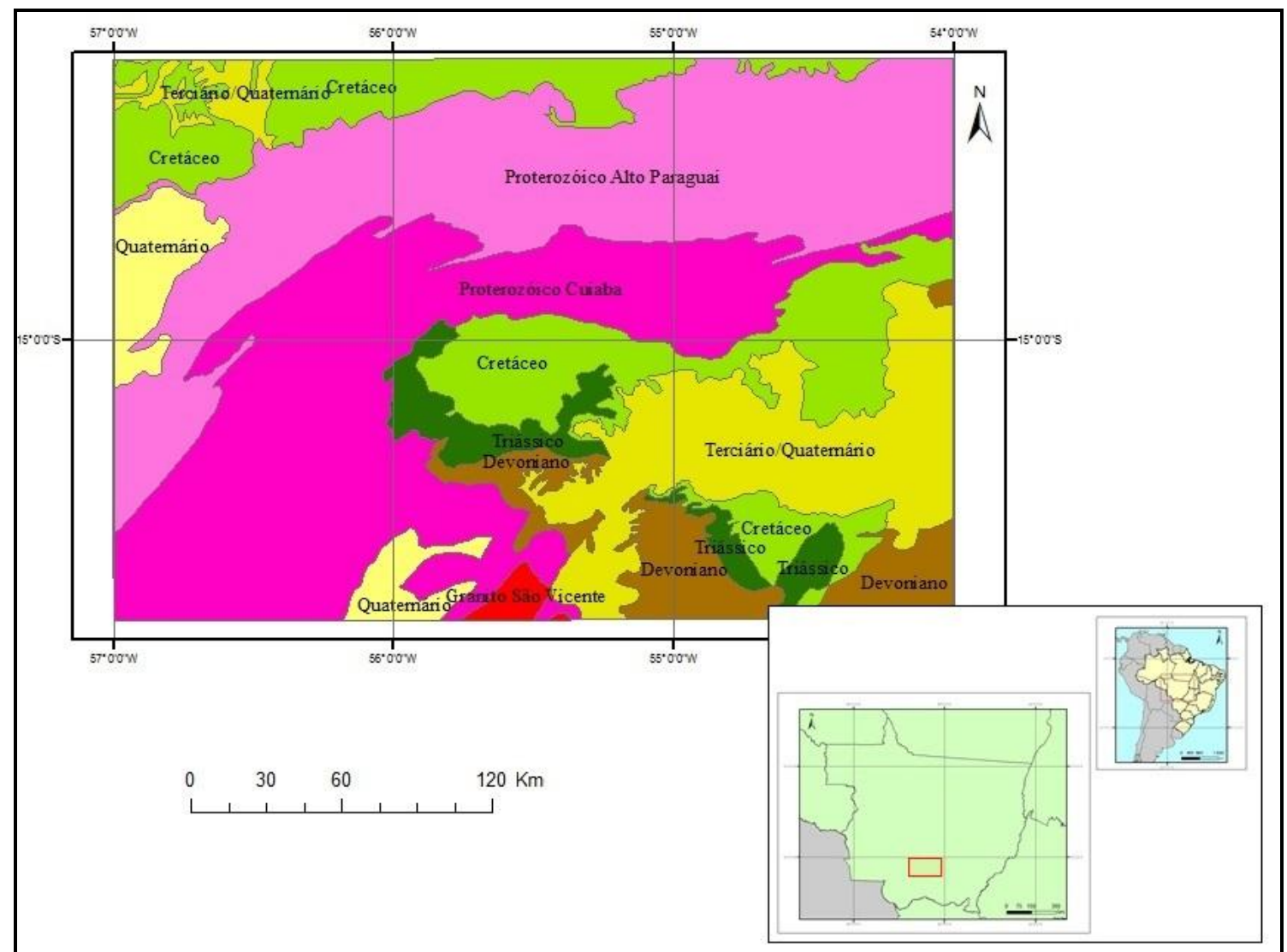

Figura 4- Mapa geológico simplificado da Chapada e arredores.

Estas evidências, relacionadas aos processos erosivos antigos, alternados com fases de sedimentação e intercalados por eventos tectônicos de grande expressividade, possibilitam estabelecer correlações quanto à morfogênese na Chapada dos Guimarães e seu entorno próximo. Como já foi exposto, a Chapada dos Guimarães e os planaltos de seu entorno próximo são mantidos pelos sedimentos da Bacia do Paraná. A cronoestratigrafia do setor noroeste desta Bacia apresenta alguns hiatos relativos a eventos deposicionais quando comparado com outras áreas da mesma. A sequência sedimentar possui em sua base sedimentos das Formações devonianas Furnas e Ponta Grossa. Estes sedimentos dão sustentação estrutural a toda região da Chapada, bem como do Planalto dos Alcantilados. Os arenitos eólicos triássicos mais recentes da Formação Botucatu afloram em área restrita, no Planalto do Casca, a noroeste da Chapada, no nível entre 400 e 600 m. Os arenitos friáveis e cretáceos do Grupo Bauru afloram também no Planalto do Casca, acima de $600 \mathrm{~m}$ de altitude, e recobrem também de forma parcial o topo da Chapada dos Guimarães. Repousam sobre estes arenitos, os materiais argilosos e altamente ferruginosos denominados por TQdl - Terciário Quaternário detrítico-laterítico. Os arenitos do Grupo Bauru no topo da Chapada são pouco espessos e desaparecem na extremidade noroeste da mesma, quando passam a aflorar os arenitos da Formação Ponta Grossa. De modo geral, a superfície de topo da 
Chapada apresenta caimento topográfico de norte e noroeste para sul, com altitudes acima de $800 \mathrm{~m}$ ao norte e noroeste e $600 \mathrm{~m}$ ao sul, quando se distingue do Planalto dos Alcantilados por ruptura abrupta de escarpa erosiva, com pouco mais de $100 \mathrm{~m}$ de gradiente topográfico.

Ao explicar-se a morfogênese da Chapada dos Guimarães, desperta a atenção o fato de que nos registros dos mapeamentos geológicos regionais, com destaque para o Mapa Geológico produzido pelo Projeto Radambrasil (BRASIL, 1982), verifica-se feixes de linhas de falhas com dominância de direção NE-SW, tanto ao sul da Chapada, na região do Planalto dos Alcantilados, como a oeste, noroeste e norte, nas estruturas dobradas onde estão as Depressões Cuiabana e Interplanáltica de Paranatinga e a Província Serrana. Essas informações vem corroborar com interpretações de outros autores, como OLIVEIRA \& MUHLMANN (1965) apud BRASIL (1982), que admitiram que tais falhamentos podem estar relacionados à mesma fase dos abatimentos tectônicos registrados mais a sudoeste, na região do Pantanal de Mato Grosso. Segundo estes autores, ocorreram arqueamentos na borda noroeste da Bacia do Paraná com eixo NE-SW. ALMEIDA (1954) já admitia que tais fatos devessem ter relações com a orogenia andina. Nesta direção, reforçam-se as considerações de OLIVEIRA \& MUHLMANN (1967), quando denominaram estes arqueamentos por "Arco de São Vicente", dando-Ihe grande significado para explicar a tectogênese regional onde se inclui a Chapada dos Guimarães.

O "sistema de falhas do centro-leste de Mato Grosso" (MEDEIROS \& MUHLMANN, 1969), apud BRASIL, 1982), com extensão de aproximadamente $2.700 \mathrm{Km}$, acompanham a faixa do Cinturão Orogenético Paraguai-Araguaia e define-se como importante lineamento estrutural a que se denominou de Lineamento Transbrasiliano por SCHOBBENHAUS FILHO et al. (1975, apud BRASIL, 1982). Esses processos geotectônicos foram reativados ao longo do Terciário conforme os autores supracitados, e são os responsáveis pelos basculamentos e rebaixamentos dos blocos estruturais que colocaram em maior elevação o conjunto de unidades de relevo onde estão a Chapada dos Guimarães e os planaltos circundantes, todos fortemente dissecados e marcados pelos falhamentos regionais.

O Arco de São Vicente, acrescido pelas linhas de fraqueza das inúmeras falhas, possibilitou que processos erosivos vigorosos se instalassem e atuassem simultaneamente às atividades tectônicas, promovendo rebaixamentos generalizados ao longo do Terciário e Quaternário e esculpindo os Planaltos dos Alcantilados e do Casca. Esses processos erosivos exumaram parcialmente os sedimentos da Bacia do Paraná, ao mesmo tempo em que esculpiram as depressões circundantes. Tais processos expuseram parcialmente as superfícies de erosão pré- 
Devonianas, que atualmente configuram o piso das Depressões Cuiabana e Interplanáltica de Paranatinga.

Assim, o bloco tectônico representado pela Chapada dos Guimarães ficou mais preservado, em razão de ter sido menos afetado no seu corpo principal por fraturas e falhas do sistema de falhamentos regionais. O topo plano a pouco erodido, com cobertura dos arenitos do Cretáceo e dos materiais argilo-concrecionários, é testemunho do baixo potencial erosivo pelo qual a superfície tem sofrido nos últimos tempos.O material detrítico-laterítico mapeado e datado por BRASIL (1982) como TQdl parece mais tratar-se de uma unidade edafoestratigráfica, fruto de longo processo de pedogenização de fácies mais argilosas dos sedimentos do Cretáceo, do que propriamente um estrato sedimentar específico do Terciário-Quaternário.

As dificuldades de encontrarem-se na área de estudo testemunhos que possam demonstrar, por meio de depósitos correlativos, geoindicadores das condições climáticas atuantes nos processos erosivos regionais, fazem com que não se possa afirmar com segurança que a região passou por fases denudacionais alternadas de climas áridos e úmidos. De qualquer modo, seguindo preceitos de AB'SÁBER (1949,1960,1972), que defende as alternâncias seco-úmido correlacionáveis aos períodos glaciais e interglaciais do Terciário Superior ao Quaternário recente, é provável a ocorrência de tais processos climáticos na região. Estas condições alternadas entre climas semiáridos à áridos com tempos quentes e mais úmidos podem ter influenciado de forma diferenciada as erosões, ora por processos predominantemente mecânicos (ambientes secos), ora por processos físico-químicos (ambientes mais úmidos). Pesquisas nos mais de $400 \mathrm{~m}$ de espessura dos sedimentos da Formação Pantanal, presente na Planície do Pantanal de Mato Grosso poderão no futuro fornecer mais informações, trazendo à luz novas interpretações dos processos morfogenéticos regionais no contexto do Cenozóico.

\section{CONCLUSÕES}

Analisada sob a perspectiva regional, devem ser valorizados para a Chapada dos Guimarães os mapeamentos geológicos, geomorfológicos e pedológicos produzidos por inúmeros autores e instituições. Dentre eles, destacam-se os produzidos pelo Projeto Radambrasil, nas décadas de 1970 e 1980, bem como as pesquisas geológicas promovidas pelo DNPM - Departamento Nacional de Produção Mineral desde a década de 1950, os da PETROBRAS em busca de ocorrências 
petrolíferas na década de 1960 e 1970, e os de ROSS (1987, 1991), fundamentais para obterem-se informações voltadas à síntese analítica da evolução do relevo da região.

A correlação de dados e as análises possibilitaram rever interpretações morfogenéticas anteriores sobre a existência da Chapada dos Guimarães como um maciço de grande extensão de relevo elevado e de topo dominantemente plano. Interpretações apresentadas por ROSS \& SANTOS (1982) e ROSS (1987, 1991) foram revisitadas; deste modo, consideraram-se superadas interpretações que tomavam a superfície de topo da Chapada e das depressões de seu entorno mero produto de ciclos de erosão por pediplanação para explicar os vários nivelamentos aplanados. Como há muitas dificuldades para demonstrar claramente que tais processos definitivamente atuaram na esculturao destes relevos, as informações geotectônicas correlacionadas com os arranjos estruturais da litologia e a macro-compartimentação do relevo ofereceram maior segurança para interpretação dos resultados aqui apresentados.

Assim sendo, sem ignorar a significativa importância dos processos morfoclimáticos na morfogênese e configuração do relevo da Chapada dos Guimarães e arredores, neste trabalho valorizaram-se os aspectos morfoestruturais no conhecimento da origem e evolução do relevo regional.

Pode-se afirmar que a Chapada dos Guimarães é produto da combinação de processos geotectônicos desencadeados (movimentação crustal em razão da abertura do Atlântico, orogenia Andina e soerguimentos generalizados da plataforma sul- americana a partir do Jura-Cretáceo, estendendo-se por todo o Cenozóico), somados aos arqueamentos dômicos ao longo dos grandes alinhamentos estruturais, como o que ocorre ao longo da faixa de dobramentos Paraguai-Araguaia (Arco de São Vicente).

É fato que as movimentações crustais possuem momentos de maior ou menor atividade, com fases mais estáticas e outras mais dinâmicas ao longo dos tempos geológicos. Estas não interrompem os desgastes erosivos, que podem ser mais ou menos atuantes dependendo dos momentos tectônicos mais ativos ou menos ativos de um lado e das agressividades climáticas do outro. Verifica-se, portanto, que os processos erosivos desencadeados por estas movimentações crustais meso-cenozóicas citadas são contínuos e concomitantes aos processos de arqueamento. Tal fato implica na interpretação de que a abertura e rebaixamento das depressões circundantes, bem como das escarpas, topos da Chapada e dos Planaltos rebaixados em seus arredores foram gerados ao longo de mais de sessenta milhões de anos, e não como suposto por AB'SABER (op. 
cit.), ao afirmar que tais processos denudacionais responsáveis pela origem destas unidades de relevo seriam plio-pleistocênicos, ou seja, possuiriam apenas três ou quatro milhões de anos.

\section{BIBLIOGRAFIA}

AB'SABER, A.N.-1949-Regiões de Circundenudação Pós-Cretáceo no Planalto Brasileiro, in Boletim Paulista de Geografia, 1-São Paulo, 1-21-

AB'SABER, A.N.-1969-Ritmo da Epirogênese Pós-Cretáceo e Setores das Superficies Neogênicas em São Paulo, in Geomorfologia 13- IGEOG-USP- São Paulo,

AB'SABER, A.N.-1960-Posição das Superficies Aplainadas no Planalto Brasileiro, in Noticiais Geomorlogicas 20, PUC-Campinas, 10-22

AB'SABER, A.N.-1972-Participação das Depressões e Superficies Aplainadas na Compartimentação do Planalto Brasileiro, in Geomorfologia 28, IGEOG-USP, São Paulo, 20 p.

ALMEIDA, F.F.M.de-1954-Geologia do Centro-leste de Mato Grosso, Bol.da Div.de Geologia e Mineralogia-150, Rio de Janeiro, p.1-97

ALMEIDA,F.F.M.de-1967-Origem e Evolução da Plataforma Brasileira, Boletim da Divisão de Geologia e Mineralogia-241, Rio de Janeiro, p.1-38

ALMEIDA, F.F.M.de 1964-Geologia do Centro-oeste Matogrossense, Boletim da Divisão de Geologia e Mineralogia-215, Rio de Janeiro, p.1-133

BRASIL- 1982-Ministério das Minas e Energia-SG-Projeto Radambrasil, DNPM-Depto.Nacional da Produção Mineral, SD-21-Folha Cuiaba-Geologia, Geomorfologia, Pedologia,Vegetação, Uso Potencial da Terra- Rio de Janeiro, p.541

OLIVEIRA, M.A.M.; MUHLMANN, H.-1965- Geologia de Semi-detalhe da Região de Mutum, Jaciara, São Vicente e Chapada dos Guimarães-Petrobras-DEBSP, rel.interno- Ponta Grossa-62p.

OLIVEIRA, M. A. M.; MUHLMANN-1967-Observation on the Geology of Chapada Guimarães, Mato Grosso.Rel.Interno, Ponta Grossa, 362p. 
ROSS, J.L.S.; SANTOS, L.M.- (1982)-Geomorfologia da Folha SD-21-Cuiabá, in Levantamento dos Recursos Naturais-Projeto Radambrasil,MME- Vol.26- Rio de Janeiro, p.195-256

ROSS, J.L.S- (1987)-Estudo e Cartografia Geomorfológica da Província Serrana de Mato GrossoTese de Doutorado apresentada à FFLCH-USP-São Paulo, 360p.

ROSS, J.L.S- (1991)- Contexto Geotectônico e a Morfogênese da Província Serrana de Mato Grosso, in Revista do Instituto Geológico-SMA-SP, 12 São Paulo, p.21-37

SCHOBBENHAUS FILHO et al. -(1975)-Carta Geológica do Brasil ao Milionésimo-Folha GoiasDNPM-Brasilia, 114p.

Artigo submetido em: 26/04/2014

Artigo aceito em: 16/09/2014 